http://www.sttpb.ac.id/e-journal/index.php/kurios

\title{
Berteologi dan Melayani
}

\author{
Jelita Sihite \\ Sekolah Tinggi Teologi Pelita Bangsa Jakarta
}

\section{Pendahuluan}

\section{Sebuah tantangan dan kesempatan}

Tugas rangkap para Pelayan Kristus adalah "berteologi dan melayani", secara esensial keduanya menyatu. Tidak dapat disebut demarkasi (pemisahan) seteologi cara tegas. Berteologi yang benar adalah pelayanan itu sendiri, karena teologi pada dasarnya adalah usaha orang percaya untuk mengenali Allahnya berdasarkan pernyataan-Nya di dalam dan melalui Yesus Kristus sebagaimana dinyatakan dalam Alkitab. Ini hanya bias dilakukan (sebenarnya) dengan sikap melayani Allah (Theos), karena Theo situ tidak hanya petut menjadi 'obyek' studi, namun secara simultan juga harus sebagai 'subyek'nya. Karena itu jika tidak dalam sikap melayani Allah, sudah pasti teologinya keblinger (sesat). Berteologi semacam itu tidak lagi dilandasi rasa "takut akan Tuhan" (Ams 1:7) dan pastilah melahirkan kesesatan belaka. Sebaliknya, jika 'melayani' dalam bentuk apapun, pada dasarnya adalah berteologi itu sendiri. Tidak ada yang dinamakan 'melayani' tanpa 'berteologi'. Jika melayani tanpa berteologi yang benar akan sama dengan membangun rumah diatas pasir yang tidak akan tahan uji dari terpaan angin pencobaan. Pada gilirannya ia akan lenyap dengan sendirinya.

Untuk itu Pelayan Kristus harus menjadi "teolog-pelayan", yaitu seorang yang piawai dalam berteologi, namun berhati pelayan Tuhan yang setia. Pelayan seperti itu tidak hanya menjadi seorang yang menguasai teologi (teoritis) di kepala sedang hatinya 'jauh' dari Tuhan. Sebaliknya pada saat yang sama Pelayan Kristus juga harus menjadi "pelayan-teolog"yaitu hamba Tuhan yang melayani dengan panggilan dan visi, kesetiaan dan ketaatan yang jelas, tetapi juga memiliki dasar teologi yang jelas dan benar. Jangan sekedar memiliki semangat pelayan yang berkobar-kobar, namun tanpa pemahaman teologi yang benar. Tentang hal ini, rasul Pertus mengingatkan: "Tambahkanlah kepada 
imanmu kebajikan, dan kepada kebijakan pengetahuan" (II Pet 1:5). Dengan dasar teologi yang kokoh tidak akan mudah diombang-ambingkan oleh rupa-rupa angin pengajaran yang menyesatkan (Ef 4:14).

Tentang kedua hal tersebut (berteologi dan melayani) Paulus memperingatkan Timotius (dan kita): "Awasilah dirimu sendiri dan awasilah ajaranmu.bertekunlah dalam semuanya itu, karena dengan berbuat demikian Engkau akan menyelamatkan dirimu dan semua orang yang melanggar engkau” I Timotius 4:16. Artinya, pelayanan dan pengajaran akan berdampak serius bagi diri sendiri dan keselamatan orang lain. Karena itu keduanya harus dilakukan dengan sungguh, baik dan benar dihadapan Tuhan. Apolos member contoh yang baik dalam Kisah Para Rasul 18:24-28. Ia seorang yang sangat mahir kitab suci (teolog), namu ia juga seorang yang bersemangat dalam pelayanan, dan memiliki kerendahan hati yang luar biasa. Dengan itu ia dicatat sebagai orang yang sangat 'berguna' bagi Tuhan dan sesame.

Untuk memelihara keselarasan antara 'berteologi dan melayani' secara tepat benar inilah dibutuhkan pimpinan Roh Kudus. Pelayan Kristus harus mengikuti pimpinan Roh Kudus, karena secara kontekstual tantangan berteologi dan melayani sangatlah tidak sederhana. Sekarang ini kita sedang berada ditengah 'hingar-bingarnya' jagad teologi masa kini dengan berbagai corak dan bentuknya yang beragam. Dari yang amat rasionalis sampai yang terlampau mistis. Begitu juga dalam panggung pelayanan masyarakat Kristen masa kini. Kita bertemu denga rupa-rupa bentuk pelayanan yang dibangun diatas berbagai motif yang berbeda. Dari yang mengklaim ayat-ayat Alkitab secara 'membabi-buta' sampai yang jelas-jelas menolak keabsahan Alkitab sebagai Firman Allah. Ditambah lagi dengan lahirnya trend Kebangkitan agama-agama yang pada gilirannya telah melahirkan juga gerakan-gerakan radikalisme disemua agama menjadi fenomena yang tak dapat diabaikan. Di sinilah kita harus mencermati dengan sungguh-sungguh tantangan kontekstual dalam berteologi dan melayani.

\section{Pembahasan}

\section{Tantangan berteologi}

Untuk memahami tantangan berteologi masa kini tidaklah mungkin melepaskannya dari runtut pemikiran berteologi dalam sejarah Kristen. Patut kita renungkan sejenak kilas balik pemikiran teologi Kristen. Semula 'teologi' memang digunakan sebagai The mother of Sciences (induk dari segala ilmu), dimana teologi mendominasi segala ilmu pengetahuan. Otoritasnya menguasai segala kaidah ilmu 
pengetahuan yang dikembangkan, namun sejarah berubah ketika lahir Renaissance (abad XIV) yaitu suatu kesadaran baru terhadap keindahan dunia dan manusia. Kesadaran ini terus manusia untuk keluar dari berbagai tekanan kekuasaan Gereja yang sangat mendominir segala aspek hidup manusia pada abad sebelumnya. Kesadaran ini akhirnya menjelmakan diri menjadi Humanisme yang pada dasarnya ingin memberi porsi lebih besar kepada kebebasan manusia dalam mengaktualisasikan dirinya tanpa tekanan apapun. Pengaruh Renaissance ini nampaknya terlampau kuat dalam Gereja, sehingga teologi tidak sanggup membendung arusnya. Sejak itu ilmu pengetahuan dan kebudayaan semakin menjauhi Firman Tuhan dan malah semakin mendikte Teologi.

Sampai di sini ilmu pengetahuan mencapai masa kejayaanya yang ditandai dengan berbagai penemuan menakjubkan oleh Kepler, Galileo, Ishak Newton dan yang lainnya. Saat inilah terjadi pengagungan human nature dimana manusia menjadi kaidah tunggal untuk menentukan segala kebenaran. Akibatnya manusia kehilangan kepercayaannya kepada standart kebenaran absolute, segala sesuatu menjadi relative dan sangat bergantung pada destinasi rasio. Di pihak lain 'feeling' atau persepsi indera sebagai standart penilaian manusia ini berpengaruh besar pada pembentukan Teologi Fredrich Schleiermacher yang diangkat sebagai 'Bapak Teologi Modern' dengan karyanya: "Feeling Theology".

Fase berikut lahir Enlightenment atau masa Pencerahan yaitu suatu masa yang ditandai dengan semangat yang 'tak terbatas' terhadap peranan rasio manusia. Pencerahan ini menganggap manusia sudah mencapai kedewasaannyauntuk mengetahui segala bidang pengetahuan. Melalui rasio manusia sudah merasa cukup untuk dapat menjawab segala persoalan dan menemukan segala kebenaran, inilah abad rasio (Age of Reason). Rasiolah yang menjadi standart penentu kebenaran, sebab itu Immanuel Kant yang dijuluki sebagai Pangeran Filsafat, mengkampanyekan adanya rasio murni untuk memahami dunia yang obyektif, seakan-akan rasio sanggup mandiri tanpa pengaruh sedikitpun dari keberdosaan manusia. Malahan hidup beragama dituduh sebagai sacrificum intellectus (mengorbankan rasio), otonomi rasio ini telah melahirkan Rasionalisme yang berdampak sangat besar dalam perkembangan Teologi Modern atau Teologi Kontemporer. Dari runtut pemikiran diatas jelaslah bahwa pembentukan Teologi Modern sangat berhutang besar kepada filsafat, selain kepada Humanisme dan Rasionalisme, Teologi modern juga dipengaruhi oleh filsafat Empirisme, Materialisme, Agnistisisme, Idealisme, Eksistensialisme dan Marxisme. 
Meskipun Teologi Modern ini lahir dan berkembang di dunia barat namun kemudian pastilah Teologi juga bersemangat di dalam gereja-gereja di Asia sebagai produk misi Barat, yang terus mengerogoti sampai sekarang ini.

Fenomena lain muncul ketika istilah Kontekstualisasi diperkenalkan dalam terbitan Thelogical Education Fund tahun 1972. Istilah itu sendiri dimaksudkan untuk meng'counter Teologi Barat yang dianggap berhadapan dengan konteks kebudayaan setempat (terutama di dunia ketiga). Intilah tersebut terus diadopsi untuk melahirkan apa yang disebut sebagai teologi-teologi kontekstual, seperti: Teologi pembebasan di Amerika Latin, Teologi Dalit di India, Teologi Minjung di Korea dan sebagainya. Teologi Kontekstual tersebut memang dirancang bangun untuk menjawab tantangan local, maka tidak harus menjadi standart universal yang bias berlaku di segala tempat dan waktu. Dapatlah dibayangkan bahwa dengan cara itu dunia tidak lagi menawarkan kebenaran tunggal yang absolute, melainkan bermacam-macam kebenaran yang relative. Nampaknya inilah yang menjadi paradigm Postmodern yaitu tidak adanya titik pusat atau tidak adanya lagi standart umum yang dapat dipakai untuk mengukur, menilai atau mengevaluasi konsep-konsep dan gaya hidup tertentu.

Filsuf Postmodern, Michael Foucault menyebut keadaan ini sebagai heterotopias yang bercorak multiverse untuk menggantikan universe, maka cirri utama postmodern adalah Pluralisme. Dalam konteks ini lahirlah teologi-teologi yang bernafas pluralism, seperti yang sedang dicoba dikembangkan di Indonesia belakangan ini yaitu Teologi Religionum (Teologi Agama-agama). Ini dianggap sebagai apresiasi teologis terhadap fakta pluralism agama di Indonesia. Artinya iman Kristen juga harus sedia 'sharing' kebenaran dengan kebenaran lain diluar dirinya, karena menurut mereka semua agama adalah teman seperjalanan untuk mencari dan menuju kebenaran sejati. Konsekuensinya keunikan Kristus sebagai Juruselamat tunggal manusia berdosa hanya dianggap sebagai mitos belaka. Finalitas Kristus sebagai satu-satunya jalan keselamatan tidak lagi harus dipertahankan, tidak boleh lagi ada satu anggapan yang mengklaim dirinyalah yang paling benar karena setiap kebenaran hanya relative adanya. Fakta ini menggiring semua orang untuk menyatukan dunia menjadi mac World dengan tuntutan sinkretisme global. Inilah tantangan riil yang harus kita hadapi untuk berteologi dengan tepat benar. 


\section{Tantangan Melayani}

Beragamnya pola berteologi diatas tentu sangat berpengaruh secara signifikan terhadap pelayanan Kristen, karena produk-produk teologi dilahirkan dan dikembangkan di dalam Gereja (masyarakat Kristen), karena itu Gereja pulalah yang akhirnya menanggung segala resiko yang diakibatkannya. Teologi Modern dan Postmodern telah 'memaksa' Gereja untuk menambah atau mengurangi kebenaran firman Tuhan. Kaum rasionalis menolak hal-hal supranatural, menurut mereka mujizat hanyalah mitos karena merupakan fakta irasional, Alkitab juga ditolak sebagai Firman Tuhan yang diinspirasikan Roh Kudus (theopneustos= yang dihembusi/diilhami Allah), sementara itu kaum Romantis terus terjatuh kedalam berbagai pengalaman-pengalaman personal yang sangat mistis dan sulit dipertanggungjawabkan secara obyektif. Yang penting bagi mereka adalah hubungan pribadi dengan Tuhan, maka ia boleh melakukan apa saja seperti yang diperintahkan Tuhan kepadanya secara individual.

Kebenaran Alkitab sebagai firman Tuhan secara obyektif diabaikan, yang penting Tuhan berbicara kepada saya secara pribadi tanpa harus mengujinya dengan kebenaran Alkitabiah. Ini jelas pewujudan dari neoeksistensialisme dan dukungan kepada filsafat empirisme. Sedangkan kaum pluralis, terus menyibukkan diri dengan membangun kebenaran bersama' yang sangat kental dengan manusia sinkretisme. Untuk tujuan itu kaum pluralis rela menyangkali keunikan dan finalitas Kristus serta mendefinisikan ulang soteriologi (doktrin keselamatan) Kristen dalam 'setting' pluralism yang dianggapnya sebagai paradigma baru berteologi. Implikasi paling nyata tentu terlihat dibidang misi, karena tidak akan ada lagi keharusan memberitakan Injil kepada semua bangsa, karena itu harus dibuat reinterpretasi terhadap Amanat Agung Tuhan Yesus Kristus (Mat 28:19-20).

Terhadap semua fenomena pelayanan di atas beberapa orang menulis buku untuk memperjelas permasalahannya dan mengantisipasi segala kemungkinan untuk melindungi masyarakat Kristen dari berbagai bentuk penyelewengandalam pelayanan. Diantaranya, Jonathan D. James membahas berbagai Gerakan Penipuan di Akhir Zaman. Ia terutama mengupas pengaruh New Age Movment dalam Gereja. George Otis Jr menulis Trademark Tuhan yang secara khusus ingin menolong orang percaya untuk bias mendeteksi sebuah pelayanan apakah sungguh berasal dari Tuhan atau bukan. Dalam bukunya, ia menyingkapkan tujuh karakteristik (trade mark) Tuhan yaitu: Otoritas, kejujuran, kerendahan hati, kasih, kreatifitas, produktifitas dan kesabaran. 
Dengan trademark itu diharapkan kita sanggup membedakan bentuk pelayanan manakah yang sungguh berasal dari Tuhan dan manakah yang bukan.

Florence Bulle menulis The Many Faces of Deception (berbagai tipuan dalam pelayanan), ia membukakan macam-macam motif yang berpengaruh dalam pelayanan Kristen, seperti: hedonism, materialism, humanism, spiritisme, psikologi, dan gerakan zaman baru. Berbagai motif pelayana tersebut telah membuat ketidak seimbangan kebenaran dalam Gereja, karenanya harus terus diwaspadai. Untuk itu Dick Iverson menulis Maintaining Balance When Winds of Doctrine Blow (tetap seimbang menanggapi rupa-rupa angin pengajaran), ia bermaksud memperlengkapi orang percaya untuk membedakan kebenaran. Rumitnya tantangan berteologi dan melayani seperti diatas mengharuskan kita untuk sungguh menggumulinya di hadapan Tuhan agar Roh Kudus membimbing kita dalam berteologi dan melayani bersesuaian dengan kehendak-Nya.

\section{Bimbingan Roh Kudus dalam Berteologi dan Melayani}

Mengapa Roh Kudus mesti memimpin kita dalam berteologi dan melayani? Tuhan Yesus sendiri sebelum memulai seluruh aktifitas pelayanan-Nya dipimpin oleh Roh Kudus (Mrk 1:12) dan kemudian memproklamirkan bahwa Roh Kudus ada padaNya sebagai penggenapan dari nubuat nabi Yesaya (Luk 4:18; Yes 61:1-2). Ini menunjukkan bahwa eksistensi Roh Kudus dalam diri orang percaya (termasuk para hamba Tuhan) merupakan bagian vital dalam hidup dan pelayanannya. Rasul Petrus setelah mengalami peristiwa Pentakosta, ia terus dibimbing Roh Kudus dalam pelayananya (Kis 10:19), bahkan rasul Petrus menyatakan dirinya sebagai tawanan Roh (Kis 20:22). Artinya ia berada dalam penguasaan Roh Kudus sepenuhnya, apa yang diperbuatnya dan perkataanya dalam hidup dan pelayanannya senantiasa menurut Roh (Rom 1:4; 7:6; 8:4-5). Akhirnya iapun menyimpulkan: “Jikalau Dipimpin Roh berarti: kita hidup oleh Roh, baiklah kita juga dipimpin oleh Roh"(Gal 5:25).

Mengakui Roh Kudus sebagai pribadi yang hadir dan tinggal didalam kita. Menyadari kehadiran-Nya dalam hidup kita memungkinkan kita mengalami pimpinanNya. Mempercayakan diri kepada-Nya dan mengharapkan pertolongan-Nya dalam segala kesulitan hidup kita dan mengindahkan Dia sebagai Pribadi yang sudah menanggung beban kita serta bersedia menolong setiap saat kita memerlukan

Jika kita mau dipimpin Roh, kita harus sedia meminta nasihat dari pada-Nya. Jika kita bersandar kepada-Nya dan mengikutsertakan Dia dalam segala sesuatu yang hendak 
kita lakukan, niscaya Ia akan memimpin jalan kita. Jika kita mau dipimpin Roh, kita harus menaati perintah-Nya, karena Roh Kudus dikaruniakan Allah kepada semua orang yang taat kepada Dia (Kis 5:32). Kita harus sejalan dan selangkah dengan Roh Kudus. Kita harus selalu mendengar suara-Nya dan mengikuti pimpinan-Nya.

Jadi, jelaslah bahwa mengikuti pimpinan Roh Kudus mutlak diperlukan oleh setiap hamba Tuhan yang hendak berteologi dan melayani dengan baik dan benar. Pertanyaannya mengapa harus kepada Roh Kudus kita meminta bimbingan? Jawabannya ialah: Roh Kudus adalah Roh Kebenaran (Yoh 14:16; 15:26; 16:13), maka Ia akan memimpin kita kedalam seluruh kebenaran. Berteologi dan melayani adalah usaha merumuskan dan melakukan kebenaran, sehingga kita sangat membutuhkan bimbingan Roh kebenaran itu agar tidak bersalah dan tersesat. Roh Kudus sedia mengajar kita ketika kita dalam kesulitan (Luk 12:12). Dalam berteologi dan melayani acapkali kita menghadapi situasi sulit, pada saat itulah kita perlu bimbingan-Nya untuk mengajari kita tentang apa yang harus kita katakan dan lakukan.

Roh Kudus adalah Roh yang member kekuatan, kasih dan ketertiban (II Tim 1:7). Dia sanggup memberikan kekuatan kita dalam menghadapi segala perkara yang terjadi dalam hidup dan pelayanan kita. Dia memberikan kuasa (dunamos) untuk menjadi saksi-Nya (Kis 1:8), tidak ada satupun yang tidak sanggup Ia perbuat, sebab Iapun Roh Pencipta segala sesuatu. Iapun Roh Kasih (Rm 15:30) yang penuh kelembutan dan kemurahan, Ia juga Roh Hikmat yang terus mengajari kita hidup dalam ketertiban. Demikianlah kita sangat membutuhkan kuasa-Nya, kasih-Nya dan Hikmat-Nya dalam berteologi dan melayani.

Pertanyaan selanjutnya ialah bagaimanakah kita bias menerima pimpinan Roh Kudus agar kita diajari kebenaran dan mengalami kasih dan kuasa-Nya? Ada banyak cara yang bias dipakai Roh Kudus untuk memimpin kita, di antaranya: Roh Kudus memimpin kita dengan memakai Firman Tuhan. Dia bisa memakai Alkitab yang kita baca untuk berbicara kepada kita, disaat yang lain Dia memakai Firman Allah yang dikhotbahkan untuk berbicara secara khusus kepada kita. Firman itu Pelita dan terang bagi jalan hidup kita (Mzm 119:105). Roh Kudus memimpin kita melalui perkataan langsung. Pada saat tertentu Roh Kudus berbicara dalam hati kita untuk menyatakan maksud-Nya (band Kis. 16:6), untuk ini dibutuhkan kedewasaan rohani dalam hubungan pribadi dengan Tuhan dan perlu dukungan persekutuan orang percaya yang 
sungguh matang rohaninya, agar perkataan Roh tersebut sungguh bersesuaian dengan firmanTuhan.

Roh Kudus memimpin kita melalui keterlibatan aktif dalam suatu situasi tertentu. Informasi yang kita dengar dan doakan dengan sungguh bisa menjadi media bagi Roh Kudus untuk menyampaikan maksud-Nya kepada kita (bnd Yoh 4:35-37). Roh Kudus memimpin kita melalui kejadian dan keadaan tertentu. Bisa terjadi bahwa peristiwa tertentu yang kita alami bukanlah 'kebetulan' semata-mata melainkan Roh Kudus hendak memakainya untuk memimpin kita (bnd Luk 23:26). Roh Kudus memimpin melalui persekutuan. Roh Kudus juga memakai persekutuan orang percaya untuk menyampaikan kehendak-Nya bagi kita (bnd Kis 11:22-26). Roh Kudus memimpin kita melalui kesaksian sejahtera Ilahi. Jalan Tuhan pastilah diiringi sejahtera Tuhan.

Ada begitu banyak cara yang Roh Kudus bisa pakai untuk memimpin kita. Roh Kudus sendirilah yang menentukan cara manakah yang akan dipakai-Nya untuk menjelaskan sesuatu kepada kita. Kita tidak bisa menentukan sendiri berdasarkan keinginan kita yang cenderung dipengaruhi keinginan daging kita. Demikian jugalah ketika kita berteologi dan melayani, kita membutuhkan bimbingan Roh Kudus dan sedia menaati-Nya. Untuk itu ada beberapa karakteristik yang bisa menjadi tanda bagi seorang hamba Tuhan yang mengikuti pimpinan Roh Kudus dalam berteologi dan melayani, yaitu:Ia telah dilahirkan oleh Roh (Yoh 3:3-5), Ia menjadi anak Allah (Yoh 1:12), ia hidup oleh Roh (Gal 5:25), Ia menerima Kristus dan menjadi ciptaan baru (II Kor 5:17). Otonomi rasio harus diserahkan kedalam kematian Kristus agar mengalami pembaharuan didalam Dia (Rm 12:1-2), karena Kristuslah sumber hikmat dan pengetahuan kita (bnd Kol 1:18-19; 2:3). Ini menjadi syarat utama bagi seorang yang ingin mengikuti pimpinan Roh Kudus. Ia sendiri haruslah telah didiami Roh Kudus dalam hidupnya (bnd I Kor 6:19-20). Tanpa itu sulit baginya untuk memahami apa yang dikatakan Roh kepadanya.

Menerima otoritas Alkitab sebagai Firman Allah. Alkitab adalah karya Roh Kudus karena keseluruhan Alkitab diilhamkan Roh Kudus, karena keseluruhan Alkitab diilhamkan Roh Kudus (II Tim 3:16). Sebab itu Alkitab adalah firman Allah yang juga menjadi pedang Roh (Ibr 4:12; Ef 6:17). Berteologi dan melayani dengan benar jika mendatangkan: pembaharuan hidup, rasa takut akan Tuhan, kesanggupan menghadapi kuasa kegelapan, pertumbuhan iman dan semangat pemberitaan Injil dan Misi. 
Jika tanda-tanda tersebut tergenapi didalam diri seorang hamba Tuhan, maka teologi dan pelayanan yang dihasilkan ada dalam bimbingan Allah yang Kudus.

\section{Penutup}

Konteks berteologi dan melayani di abad XXI ini tidaklah sederhana. Dibutuhkan seorang hamba Tuhan telah menaruh Roh-Nya untuk berbicara atas nama Allah kepada bangsa-bangsa (Yes 42:1, 2, 4). Orang seperti itu akan berteologi dan melayani dengan dasar Kristus dan Alkitab sebagai firman Allah untuk menghidupkan iman dan menghantar orang kepada Kristus demi keagungan nama-Nya di seluruh bumi, karena segala sesuatu dari Dia, dan oleh Dia, dan kepada Dia: bagi Dialah kemuliaan sampai selama-lamanya! (Rm 11:36).

\section{Referensi}

AB, Simponi. Mengikuti Pimpinan Roh, Bandung: Kalam Hidup, 1994

Bulle Florence. Berbagai Tiupan Dalam Pelayanan, Malang: Gandum Mas, 1997

D. James Jonathan. Gerakan Penipuan di Akhir Zaman. Bandung: Lembaga Literatus Baptis, 1984

Iverson, Dick. Tetap Seimbang Menanggapi Rupa-Rupa Angin Pengajaran, Jakarta: Harvest Publication House,

J.Grensz Stensly. Primer On Postmodernisme. Yogyakarta: Yayasan Andi, 1996

Linnemann, Eta. Teologia Kontemporer :IImu atau Praduga. Batu, Malang-YPPII, 1991

Octavianus Petrus. Gereja Memasuki Abad XX., Batu, Malang: YPII, 1998

Scheunemann V. Injil, Iman dan IImu. Batu, Malang: YPPII, 1980

Susabda, Yakub. Teologi Modern. Jakarta: LRII, 1990 